\title{
Effect of pyridine and pyridine with substituent on photoluminescence of nanoparticles CdS prepared by liquid -liquid interface reaction
}

\author{
Salma M. Shaban, K. T. Mahdi, A. S. Ahmed
}

Department of Physics, Science College, Baghdad University, Iraq

E-mail: asaaabi@gmail

\begin{abstract}
Liquid - liquid interface reaction is the method for preparation nanoparticles (NP'S) which depend on the super saturation of ions that provide by using the system that consist from toluene and water, the first one is above the second to obtain nanoparticles (NP's) CdS at the interface separated between these two immiscible liquid. The structure properties were characterized by XRD-diffraction and transmission electron microscopy.

The crystalline size estimate from X-ray diffraction pattern using Scherer equation to be about $7 \mathrm{~nm}$, and by TEM analysis give us that ananosize is about $5 \mathrm{~nm}$ which give a strong comparable with Bohr radius. Photoluminescence analysis give two emission peak, the first one around the $380 \mathrm{~nm}$ and the second around the $760 \mathrm{~nm}$ which indicate to the band edge and surface defect emission respectively and the intensity of these emission change with the change of the pyridine substituent.
\end{abstract} Key words

Nanoparticle, LiquidLiquid Interface reaction, surface modification, Photoluminescence.

Article info.

Received: May. 2015

Accepted: Oct. 2015

Published: Dec. 2015

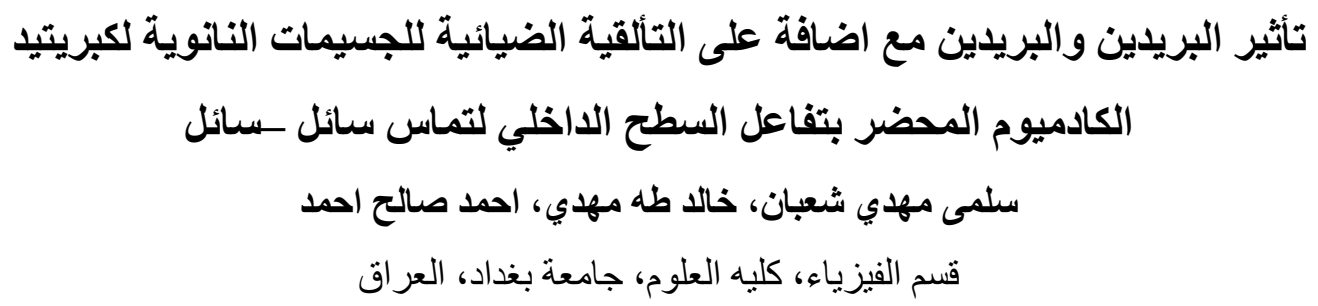

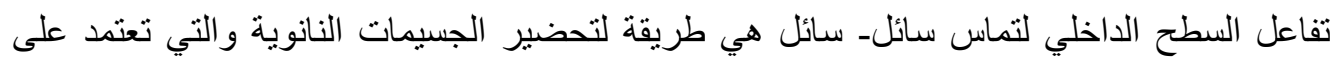

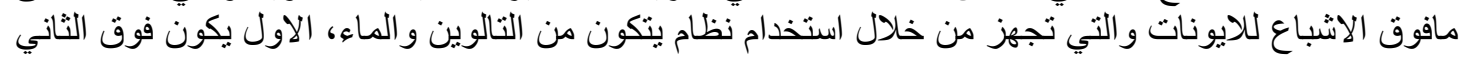

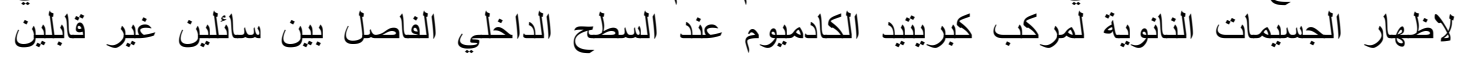
للامنز اج. صفات التركيب شخصت بو اسطه حيود الاشعه السينية و المجهر الآلكتروني الماستح.

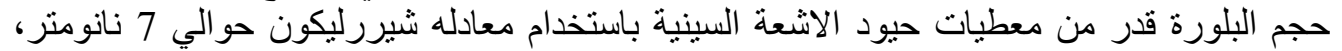

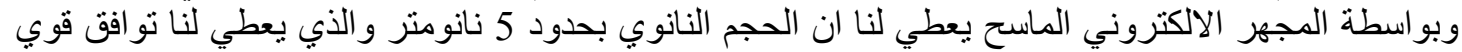

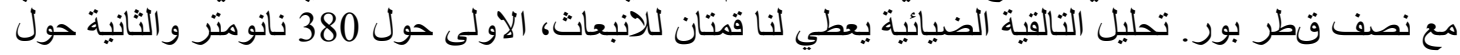

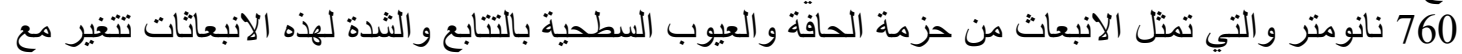
تغير اضافة البريدين.

\section{Introduction}

Semiconductor nanoparticles have a specific optoelectronic properties, these specific properties can be attribute to the high surface to volume ratio [1]. To improve these properties, the surface of the nanoparticles can be modification [2], 
these modification can be done through the chemical method [3-5]. one of these method is by capping with organic material such as pyridine and pyridine with substituent family such as 2-picoline [6]. The aim behind this modification is to minimize surface defect and increase luminescence efficiencies [7].

Cadmium sulfide nanoparticles has a big amount of interest due to the engineering the band gab depending on the size of the particles [8]. And with suitable surface modification we can bond these particles with organic legend at the surface of nanoparticles and these play a main role by reducing the defect and then enhanced luminescence efficiencies. The photoluminescence is extremely sensitive to the surface passivation. For CdS, two types of emission are possible, the band edge (BE) emission and surface defect emission that lie in the wavelength below and above $500 \mathrm{~nm}[9,10]$. The aim of this work is to study the effect of surfactant on the surface modification for NP'S CdS through the analysis of photoluminescence spectrum which is the new attempt to understand the properties of NP'SCdS.

\section{Experimental details}

1. Preparation of NP'SCdS using liquid -liquid interface reaction

The method to prepare NP'S

$\mathrm{CdS}$ by using liquid -liquid interface reaction need to pass through two step, the first step is to prepare the precursor which act as the source of the Cadmium and the second step the reaction at the interface between two immiscible liquid to get a NP'SCdS.

So in the first step to get the precursor cadmium diethyl ldithiocarbamate, the procedure that describe by O'Brien and R.Nomura [11] has been applied. In this procedure $(11 \mathrm{mM})$ from Sodium hydroxide dissolve in $50 \mathrm{ml}$ methanol using a magnetic stirrer. Then $(1.128 \mathrm{ml})$ diethlamine and $(0.65 \mathrm{ml})$ Carbon disulfide have been added. The solution has a pale yellow. And after that and by using the ice bath, the solution cooled to $4{ }^{\circ} \mathrm{C}$ for eight hour then $50 \mathrm{ml}$ of the methanol which dissolve in it $(5.5 \mathrm{mM})$ from Cadmium Chloride added by dropping wisely and take it under stirrer for one hour and then a yellow solid can be note which represent to produce the precursor then filtered and wished by methanol then water and at the last with methanol then dry it by oven in the temperature $\left(65-70{ }^{\circ} \mathrm{C}\right)$ for 12 hour.

And in the Second step we work to prepare the nanoparticles CdS by apply the following steps at the first dissolve $\mathrm{Na}_{2} \mathrm{~S}$ in deionized water (11.46 mg or $0.147 \mathrm{mmol}$ ) which consider as the source of sulfide. then added above it $50 \mathrm{ml}$ of toluene containing $30 \mathrm{mg}$ $(0.073 \mathrm{mmol}$.) of cadmium diethyl dithiocarbamate. the two immiscible liquid one above each other and separated by interface layer can be noticed as shown in the Fig. 1 then the beaker put into an oven held at $65{ }^{\circ} \mathrm{C}$.

And left undisturbed for 24 hour. at end of this time, a yellow thin film was found adhered to the interface of the two liquids. 


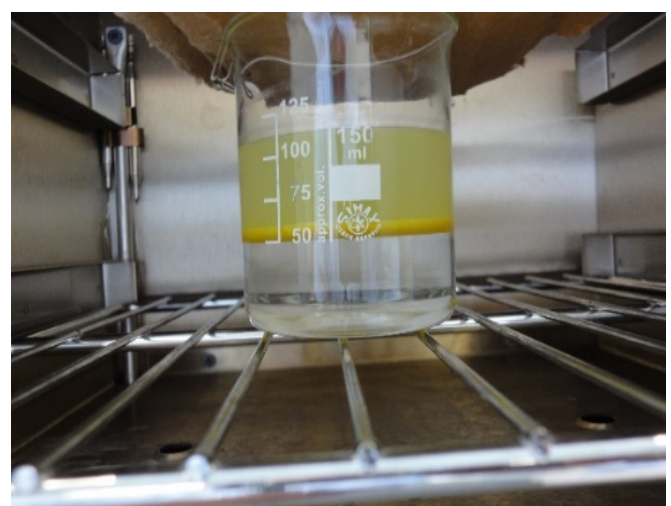

Fig.1: Layered two immiscible liquids to get the interface reaction for produce NP'S CdS.

\section{Procedure for surfactant}

We immerse $0.1 \mathrm{gm}$ from powder of nanoparticles $\mathrm{CdS}$ in the solution consist of $1 \mathrm{ml}$ of pyridine or pyridine with substituent in $9 \mathrm{ml}$ of methanol, then left it for one hour under ultrasonic vibration.

\section{Result and discussion}

1. Estimate the structure and size from X-Ray diffraction pattern

For characterization the structural for X-ray diffraction is used A Philips $X$ pert diffractometer utilizing monochromated $\mathrm{CuK \alpha}$ radiation $(\lambda=0.15406 \mathrm{~nm})$. From the $\mathrm{X}$ ray diffraction pattern which obtain in Fig. 2, it is noted a peaks at $2 \theta$ equal to $25.59^{\circ}, 42.5^{\circ}, 51.13^{\circ}$. The peaks at these $2 \theta$ can be assigned to (002), (110), (112) planes of hexagonal CdS. And we can note that the peak at $2 \theta=25.59^{\circ}, \quad 2 \theta=42.5^{\circ}, \quad 2 \theta=51.13^{\circ}$ attributed to the (002) for hexagonal structure or (111) for cubic, the (110) for hexagonal structure or (220) for cubic the (112) for hexagonal structure or [311] for cubic, But the peaks at the 24.93 are purely indicate to (100) for hexagonal structure. we consider that the deposit consist of both the cubic and hexagonal forms. Such mixed phases have been previously reported in chemically deposited $\mathrm{CdS}$ nanostructures [12-16]. So, the product are free from impurities.

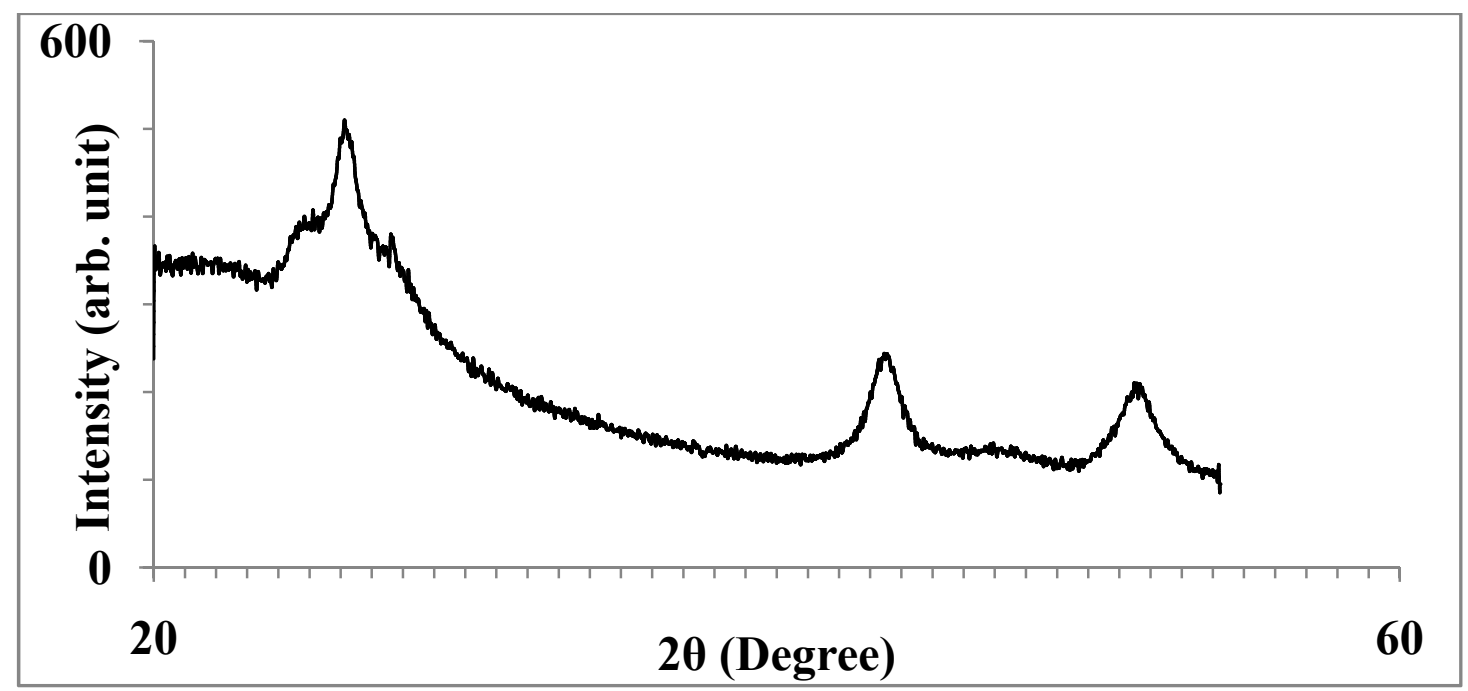

Fig.2: $X$-ray diffraction patterns obtained from nanoparticles $C d S$ prepared using the interface reaction for the system of $\mathrm{H}_{2} \mathrm{O}$ - Toluene. 
The broading of the peaks refer to a nanoscale of the size. The grain size of the particulates can be estimated using Scherrer equation:

$D=\frac{0.9 \lambda}{\beta \cos \theta}$

where $\beta$ is the full width at half maximum in radians, $\lambda$ is the wavelength of X-ray used and $\theta$ the angle of diffraction. And when apply this relation for the diffraction angle that it is clear in Fig. 2, the average size of grains was equal to $7.73 \mathrm{~nm}$ and this is when compare with Bohr radius of $\operatorname{CdS}\left(\mathrm{a}_{\mathrm{B}}=2.8 \mathrm{~nm}\right)$, the particles is in the range of nanoparticle (two or three multiple of Bohr radius or in the range 2-10 nm).

The Scherer's equation may produce results that are different from actual size[17], The boarding of the peaks may be caused by residual stresses and grain size that may be present in the grains, there is shifting in the peaks due to the Stresses within the crystal cause corresponding strains, which result in a planar spacing. A combination of compressive and tensile strains often result from the residual stresses. In order to calculate the average crystallite size including strain, we adopted the Williamson Hallmethod [18], where the strain $(\varepsilon)$ and crystallite size (D) are related to the measured $\beta$ using the following the equation:

$\beta \cos \theta=\frac{K \lambda}{D}+4 \sin \theta$

or

$\frac{\beta \cos \theta}{\lambda}=\frac{K}{D}+4 \varepsilon \frac{\sin \theta}{\lambda}$

where $\beta, \lambda$ and $\theta$ are the full-width at half maximum (FWHM) of the diffraction peaks, wavelength of the xray source and Bragg's angle, respectively. For this calculation, the most prominent peaks as shown in the Fig. 2 were analyzed. Fig. 3 represent the plots of $(\beta \cos \theta / \lambda)$ versus $\sin \theta /$ $\lambda$ ) which is a straight line. The slope of the plot gives the amount of residual strain, whereas reciprocal of intercept on the y-axis give the average particle size. Values $3.9 .56 * 10^{-3}$ and $9.4 \mathrm{~nm}$ are obtained for strain and average grain size, respectively.

\section{Fig.3: Williamson -Hall plot to determine the particle size and strain of nanoparticles CdS.}

\section{Transmission electron microscopy}

The Philips CM 200 microscope operating at $200 \mathrm{kV}$ has been used for transmission electron microscopy. Samples for TEM were obtained by deposition a methanol dispersion of the films on carbon coated $\mathrm{Cu}$ grid. Transmission electron microscopy image gives more details of the structure. From this image that obtained in Fig.4, each grains has the platelets which can easily resolved and spacing between (110) and (002) planes are clearly seen [12]. The average size of the grain can be consider around $3 \mathrm{~nm}$ which gives us a strong comparable with Bohr radius of CdS. 


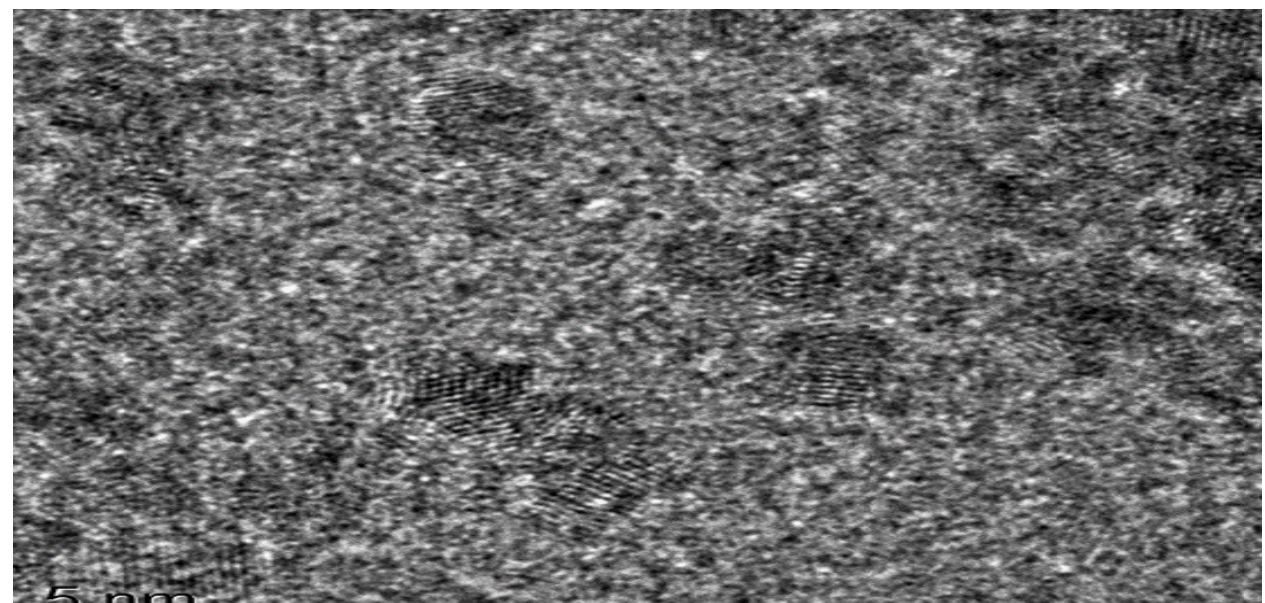

Fig. 4: Transmission electron microscopic images of NP's CdS.

\section{Photoluminescence}

At Bangor University (U.K), the spectra Max (M2) instrument that manufacture by molecular device (U.K) has been used for photoluminescence measurement. The photoluminescence spectrum recorded in the wavelength range $200-800 \mathrm{~nm}$, and the excitation is in the range (300420) $\mathrm{nm}$.

For study the effect of pyridine and pyridine with substituent family the following material has been used: pyridine, 2-methoxypyridine, 4-idopyridine, 2-methlypyridine, 4-methlypyridine, 3-ido-pyridine, 4-ethlypyridine and depending on $\mathrm{PKa}$ value which indicate the strong of nitrogen atom in pyridine ring to attack the neucliphen these material can arrangement into two group, the first one is electron donating group (EDG) which increase the density of electron on the pyridine ring, and drawl electron group (EDG) which decrease the electron density on the pyridine ring as shown in the Table 1 and 2.

Table 1: Pyridine with electron donating substituent.

\begin{tabular}{|c|c|c|c|}
\hline & Pka & $\begin{array}{c}\Delta \mathrm{Pka} \\
\left(\mathrm{Pka}_{\text {pyridine }}-\mathrm{Pka}_{\text {pyridine }+ \text { substituent }}\right)\end{array}$ & $\begin{array}{c}\text { Effect of substituent on the } \\
\text { pyridine ring }\end{array}$ \\
\hline pyridine & 5.17 & 0 & ----- \\
\hline 4-ethlypyridine & 5.78 & positive & $\begin{array}{c}\text { Increase the density of electron } \\
\text { in pyridine ring }\end{array}$ \\
\hline 2-methly pyridine & 5.96 & positive & $\begin{array}{c}\text { Increase the density of electron } \\
\text { in pyridine ring }\end{array}$ \\
\hline 4-methly pyridine & 6.02 & positive & $\begin{array}{c}\text { Increase the density of electron } \\
\text { in pyridine ring }\end{array}$ \\
\hline
\end{tabular}

Table 2: Pyridine with electron drawl substituent.

\begin{tabular}{|c|c|c|c|}
\hline & Pka & $\left(\mathrm{Pka}_{\text {pyridine }}-\mathrm{Pka}_{\text {pyridine }+ \text { substituent }}\right)$ & $\begin{array}{c}\text { Effect of substituent on } \\
\text { the pyridine ring }\end{array}$ \\
\hline pyridine & 5.17 & 0 & ---- \\
\hline 2-methoxypyridine & 3.06 & negative & $\begin{array}{c}\text { decrease the density of } \\
\text { electron in pyridine ring }\end{array}$ \\
\hline 3-idopyridine & 3.25 & negative & $\begin{array}{c}\text { decrease the density of } \\
\text { electron in pyridine ring }\end{array}$ \\
\hline 4-idopyridine & 3.9 & negative & $\begin{array}{c}\text { decrease the density of } \\
\text { electron in pyridine ring }\end{array}$ \\
\hline
\end{tabular}


So in this work the effect of pyridine and pyridine with electron donating substituent, and pyridine with electron drawl substituent on the photoluminescence of nanoparticles $\mathrm{CdS}$ has been studied. From the spectra of measurement for emission of all samples, two emission peak have been noticed, the first one due to the band edge emission (BE) and the second one due to the trapped emission, the band edge emission peak is broad, The broad character of the fluorescence can be attributed to both a number of trap states, each with a slightly different energy, and some degree of sample polydispersity [19] and the trapped emission is sharp $[20,21]$, the emission peak located in the range 620-780 nm corresponds to red emission, which is associated with Sulphur vacancies in CdS nanoparticles [22, 23], the blue emission is attributed to the radiative recombination of electron -hole pair (24), as an example, Fig. 5 give a view about these two emission peaks, which are resulted for nanoparticle CdS after treatment with pyridine and at excitation wavelength $340 \mathrm{~nm}$.

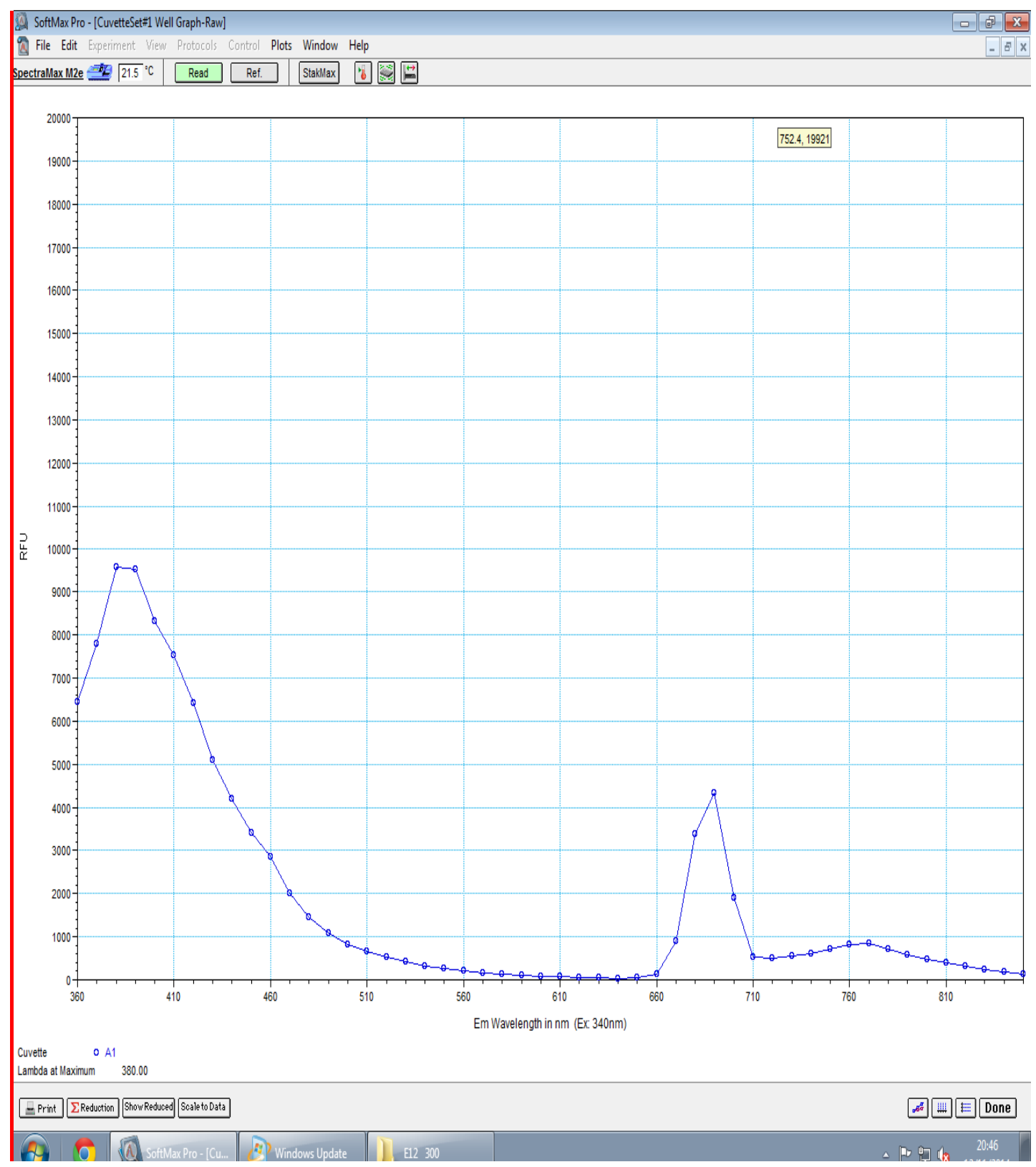

Fig.5: Photoluminescence spectrum of NP'SCdS /pyridine atexcitation wavelength $340 \mathrm{~nm}$. 
3.1Effect of electron donating substituent on band edge emission (BE)

Table 3 give us the emission wave length at maximum value of intensity with respect to excitation wave length in the band edge emission range for the nanoparticles $\mathrm{CdS}$ and nanoparticles $\mathrm{CdS}$ after treatment with pyridine and pyridine with electron donating substituent.

Table 3: Position of emission wavelength (Em.W.L.) at maximium intensity corresponding to the excitation wave length (Ex.W.L.) for nanoparticle CdS before and after surface treatment with electron donating substituent.

\begin{tabular}{|c|c|c|c|c|c|c|c|}
\hline Excitation. Wavelength (Ex.W.L.) (nm) & 300 & 320 & 340 & 360 & 380 & 400 & 420 \\
\hline $\begin{array}{c}\text { Emission. wave length (Em.W.L.) (nm ) } \\
\text { NP'S CdS }\end{array}$ & 370 & 370 & 380 & 410 & 420 & 420 & ----- \\
\hline $\begin{array}{c}\text { Emission. wave length (nm ) } \\
\text { NP'S CdS / pyridine }\end{array}$ & 370 & 370 & 380 & 410 & 420 & 420 & \\
\hline $\begin{array}{c}\text { Emission wave length (nm ) } \\
\text { NP'S CdS / 4-ethlypyridine }\end{array}$ & 370 & 380 & 390 & 420 & 420 & 420 & 440 \\
\hline $\begin{array}{c}\text { Emission wave length (nm ) } \\
\text { NP'S CdS / 2-methlypyridine }\end{array}$ & 370 & 370 & 380 & 420 & 430 & 420 & 440 \\
\hline $\begin{array}{l}\text { Emission wave length (nm ) } \\
\text { NP'S CdS / 4-methlypyridine }\end{array}$ & 370 & 370 & 390 & 420 & 400 & 420 & 440 \\
\hline
\end{tabular}

Fig.6 show the maximum intensity for each emission for nanoparticles $\mathrm{CdS}$ and nanoparticles CdS after treatment with electron donating group. the band edge emission ( $\mathrm{BE}$ ) at maximum intensity of emission for all samples accurse at the same wave length that is $\lambda_{\mathrm{em}}=380$ $\mathrm{nm}$ with same excitation wave length $\lambda_{\text {ex }}=340 \mathrm{~nm}$ which indicate that there are stability in the band edge structure, and the blue shift (the emission of bulk $\mathrm{CdS}=525 \mathrm{~nm}$ ) indicate that the effect of nanosize, but there is a change in the amount of intensity which represent to the effect of surface treatment, these treatment play two role, the first one to reduce the defect on the surface by reacting with $\mathrm{Cd}^{+2}$ which exists richly in the surface and this reduce the effect of dangling bond in the band structure and the second role to increase the electron charge density in the nanoparticles which give the more probability for electron to excited.

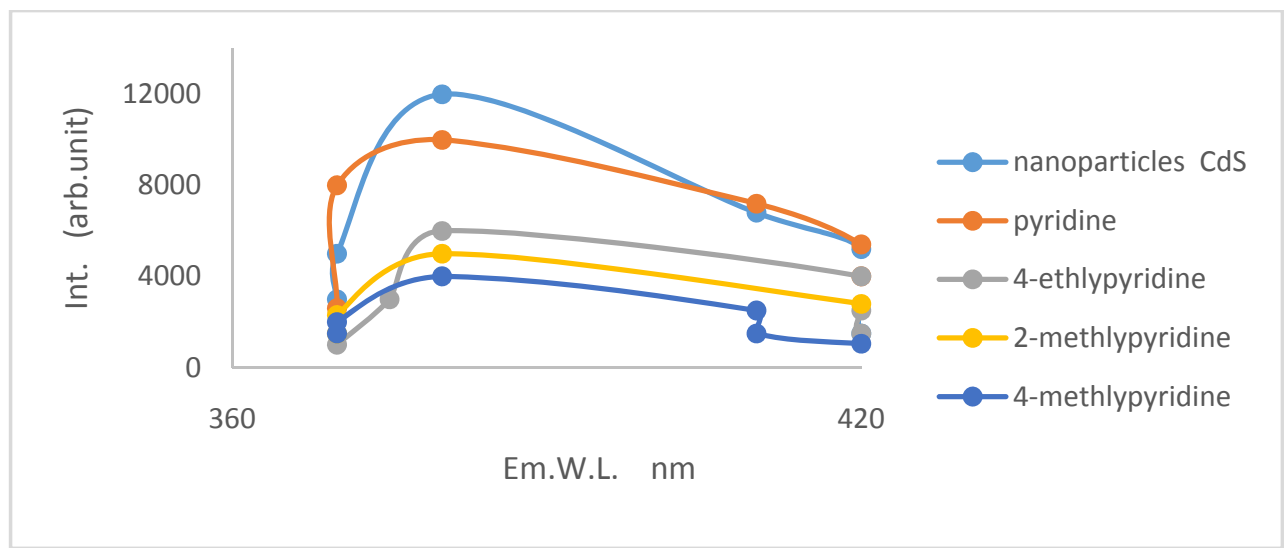

Fig.6: The maximum value of intensity for each emission for NP'SCdS before and after surface modification by pyridine and pyridine with electron donating substituent in band edge emission range. 
3.2. Effect of pyridine and pyridine with electron donating substituent on trapped emission

The wave length of emission corresponding to excitation wave length at maximum value of intensity is the same for all samples as shown in Fig.7, which indicate that there is no shift in the position of peak after treatment and this represent to that there is a stability in created of defect which mean that the method of preparation is success fulin producing nanoparticles with minimum impurity, then the reducing the defect state may be not sensitive.

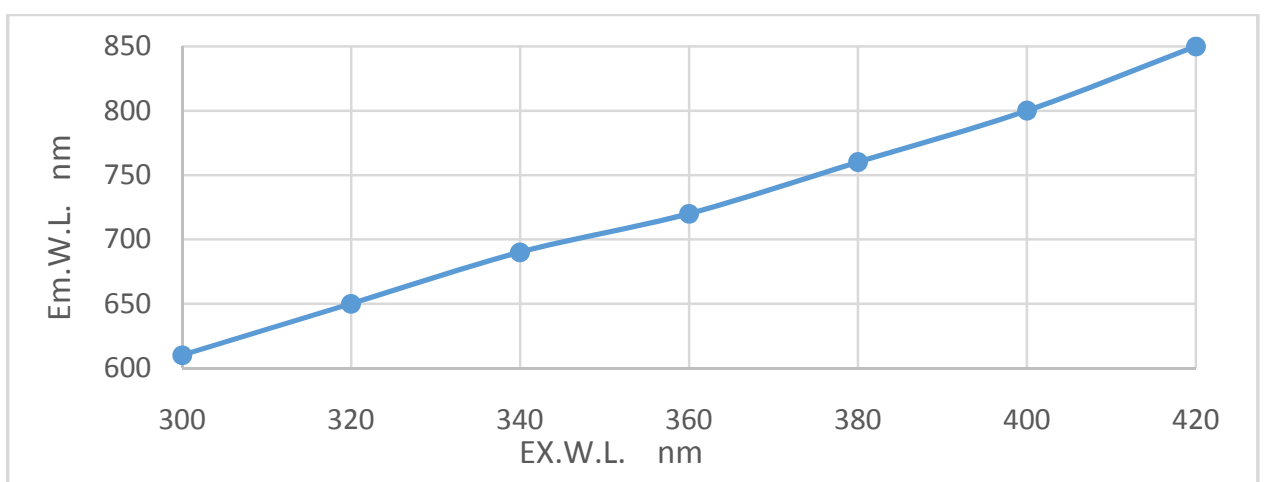

Fig.7: The emission wavelength(Em.W.L.)nm excitation wave length (nm) for photoluminescence spectra of nanoparticles CdS before and after surface modification by pyridine and pyridine with electron donating substituent.

And for all samples, the maximum intensity is at excitation wave length $(360 \mathrm{~nm})$ and the emission wave length is $(760 \mathrm{~nm})$, Fig. 8 show the maximum intensity with respect to emission wavelength for all samples, The emission in this range attributed to the state that exist at the whole of band gap which causes from the defect such as vacancies and interstitial, and because the surface play a main role in nanoparticles due to the surface to volume ratio is very large, then the treatment of the surface cause an interest effect on these defect state. For all sample the position of peak not change which indicate to the stability in structure, but the intensity of the peak change, and this can attributed to that the substituent act as electron donating which increase the charge density in nanoparticles and then increase the probability of electron to reacted with electromagnetic radiation, and the increase the amount of charge that go from high to low level, Table 4 show the change in intensity depend on the PKa value of the substituent.

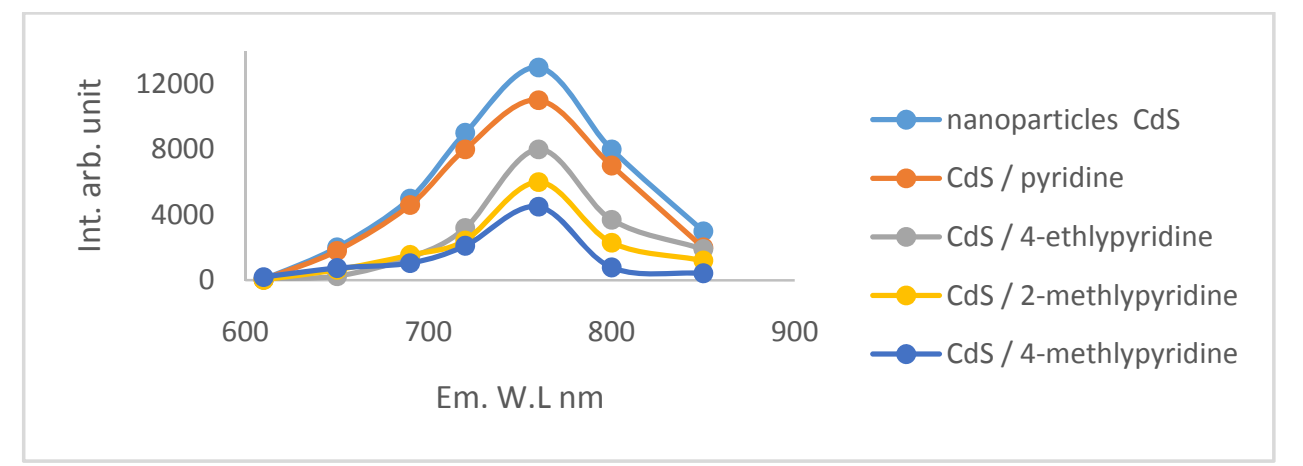

Fig. 8: The maximum value for each emission for nanoparticles CdS before and after surface modification by pyridine and pyridine with electron donating substituent. 
Table 4: Variation of the maximum intensity with respect to the pyridine electron donating substituent.

\begin{tabular}{|c|c|c|c|c|c|}
\hline & PKA & $\begin{array}{c}\text { intensity } * 10^{3} \\
\text { band edge }\end{array}$ & $\begin{array}{c}\text { intensity } * 10^{3} \\
\text { defect }\end{array}$ & $\mathrm{E}_{\mathrm{g}} \mathrm{eV}$ \\
\hline 0 & Nanoparticles CdS & & 12 & 13 & 2.8 \\
\hline 1 & Pyridine & 5.17 & 10 & 11 & 2.9 \\
\hline 2 & 4 Ethlypyridine & 5.78 & 6 & 8 & 2.95 \\
\hline 3 & 2 Methlypyridine & 5.96 & 5 & 6 & 3 \\
\hline 4 & 4 Methlypyridine & 6.02 & 4 & 4.5 & 3.05 \\
\hline
\end{tabular}

3.3 Effect of pyridine and pyridine with electron drawl substituent on band edge (EB) and defect emission

For effect of pyridine and pyridine with electron drawl substituent, two emission peak can be noticed from the emission pattern, the first one around the wave length $\lambda \mathrm{em}=370 \mathrm{~nm}$ which indicate to the band edge emission and the second emission around the wavelength $\lambda \mathrm{em}=760 \mathrm{~nm}$ which indicate to the defect emission, and there is some shift in wave length emission in band edge emission which represent to the effect of drawl substituent differ than effect of donating substituent, drawl substituent decrease the density of electron on the nitrogen atom in the pyridine ring. Table 5 gives us that when we modification by pyridine with electron drawl substituent the band gap increase as the PKa value increase and we get maximum wide band gap at stronger drawl substituent that is 4-idopyridine, from this we note that we have a small intensity at that substituent, and the intensity increase with decrease the PKa value of drawl substituent, in the other hand the nanoparticles without substituent and with modification with pyridine still have the big intensity than the other drawl substituent, this returned to that the drawl substituent will act as acceptor then will drawl the electron from the nitrogen atom in pyridine ring and this will reduce the ability of pyridine to attack the particles, then the $\mathrm{Cd}^{+2}$ act as a capture center of charges.

Table 5: Intensity for maximium emission for nanoparticles CdS before and after Modification with electron drawl substituent.

\begin{tabular}{|c|c|c|c|c|c|}
\hline & & PKA & $\begin{array}{c}\text { intensity } * 10^{3} \\
\text { band edge }\end{array}$ & $\begin{array}{c}\text { intensity } * 10^{3} \\
\text { defect }\end{array}$ & $\mathrm{E}_{\mathrm{g}} \mathrm{eV}$ \\
\hline 0 & Nanoparticles CdS & & 12 & 13 & 2.8 \\
\hline 1 & CdS / Pyridine & 5.17 & 10 & 11 & 2.9 \\
\hline 2 & CdS / 4-Idopyridine & 3.9 & 3 & 2.5 & 3.2 \\
\hline 3 & $\mathrm{CdS} / 3$-Idopyridine & 3.25 & 4.5 & 3.5 & 2.95 \\
\hline 4 & $\mathrm{CdS} /$ 2-Methoxypyridine & 3.06 & 5.5 & 4.5 & 2.9 \\
\hline
\end{tabular}

\section{Conclusion}

Liquid-liquid interface reaction is successful greener method for preparation nanoparticles $\mathrm{CdS}$, the XRD analysis give us that we have a nanosize and the radius is comparable with Bohr radius of nanoparticles $\mathrm{CdS}$ $\left(a_{B}=3 \mathrm{~nm}\right)$, and this reperesnt to preparation a nanoparticles, the photo luminescence spectra show that there are two peak the first one in around $380 \mathrm{~nm}$ which indicate to the band edge emission and the second around $760 \mathrm{~nm}$ which indicate to the defect emission, the position of these peak do not effect by surface modification but the intensity would change and this refer to the effect of electron density 
in nitrogen atom in pyridine ring which effect on the type and degree of reaction between the surftcantand surface.

\section{Reference}

[1] G.A.Matinez-Castanon, M. G. Sanchesloredo, J.R.MartinnezMendoza, F.Ruiz, Advances in Technology of Materials and Materials processing, 7, 2 (2005) 171-174.

[2] K.D.Nisha, thesis Ph.D. Faculty of Science and Humanities, Srm University, Kattankulathur, Tamilnadu, India, (2012) p.44.

[3] G. A. Martínez-Castañón, M. G. Sánchez-Loredo, H. J. Dorantes, J. R. Martínez Mendoza, G.Ortega-Zarzosa, F. Ruiz, Mat. Lett., 59 (2005) 529-534. [4] C. Li and N. Murase, J. Surf. And Coll., 20 (2004) 1-4.

[5] A. Schroedter, H. Weller, R. Eritja, W. E. Ford, J. M. Wessels, NanoLett., 2 (2002) 1363-1367.

[6] G.L.Stansfield, Ph.D. Thesis, University of Manchester, Faculty of Engineering and Physical Sciences. (2012), p.175.

[7] Y. Zhang, X. Wang, M. Ma, D. Fu, N. Gu, J.Liu, Z. Lu, Y. Ma, L. Xu, K. Chen., Applied Surface Science, 205 (2003) 256-261.

[8] L. Saravanan, S. Diwakar, R. Mohankumar, A. Pandurangan, R. Jayavel, Nanoparticles Nanomater. nanotechnol., 1, 2 (2001) 42-48.

[9] N.S.Roshima, S.K.Saravana, A.M.Uma, M.K.Siva, Journal of Nano Research, 18, 19 (2012) 49-56. [10] W.S.Chae, J.H.Ko, I.W.Hwang, R.Y.Kim, Chem.phys.Lett., 365 (2002) 49-56.
[11] P.O'Brien and Nomura, J. Mater. Chem., 5 (1995) 1761.

[12] Enteisar Albrasi, P.J.Thomas., p.O'Brien., j.Mater. Chem. C, 1 (2013) 671.

[13] D. J. Kim, Y. M. Yu, J. W. Lee, Y. D. Ghoi, Appl. Surf. Sci., 254 (2008) 7522.

[14] K.S.Ramaiah, R.Pilkington, A.Hill, R.Tomlinson, A.Bhatnagar, Mater. Chem. Phys., 68 (2001) 22.

[15] S.Mahanty, D.Basak, F.Rueda, M.leon, J. Electron. Matter., 28 (1999) 559.

[16] Y.Lo, R.Choubey, W.Yu, W.Hsu, C.Lan, Thin Solid Films, 520 (2011) 217.

[17] G.Cao, Nanostructure and Nanomaterials, Imperial College Press, London, 2004. $1^{\text {st }}$ ed.

[18] G.K.Williamson, W.H.Hall, Acta Metall., 1 (1953) 22-31.

[19] C.B. Murray, D.J. Norris, M.G. Bawendi, J. Am. Chem. Soc., 115 (1993) 8706.

[20] M.Nell and J.Marohn, J. Chem. Phys, 94 (1990) 4359.

[21] B.A.Kulp and D R.H.Kelley, J. Appl. Phys., 31 (1960) 105.

[22] C. M. Gareia, A. E. Esquivel, G. C. Puente, M. T. Velazuez, M. L. A. Aguilera, O. Vigil, L. Vallant, J. Appl. Phys., 86 (1999) 3171-3174.

[23] S.S.Emin, S.N.Nakabayashi, M.S.Villeneuve, C.M.Dushikin, J. Photochemistry and Photobiology A, Chemistry, 207 (2009) 173- 180.

[24] J. Zhang, D.X.Wei, L.L.Zhi, G. Xu. X.S.Ming, Z.X.Ping, Trans nonferrous Met. Soc. China., 17 (2007) 1367-13722. 